\title{
Musculoskeletal Consequences of Systemic Corticosteroid Misuse in A Patient with Psoriasis
}

\author{
Mohammad Moin Uddin ${ }^{1 *}$ \\ Aminuddin A Khan ${ }^{1}$ \\ Nusrat Sultana ${ }^{2}$ \\ Abu Taslim ${ }^{3}$
}

'Department of Physical Medicine and Rehabilitation Chittagong Medical College Hospital, Chittagong, Bangladesh.

${ }^{2}$ Department of Dermatology \& Veneriology Chittagong Medical College Chittagong, Bangladesh.

${ }^{3}$ Department of Physical Medicine \& Rehabilitation BGC Trust Medical College

Chittagong, Bangladesh.

*Correspondence to:

\section{Dr. Mohammad Moin Uddin}

Consultant

Department of Physical Medicine and Rehabilitation Chittagong Medical College Hospital, Chittagong, Bangladesh.

Mobile: +8801711159038

Email: moinmonju@gmail.com

www.banglajol.info/index.php/CMOSHMCJ

\begin{abstract}
This is a case history of a patient with psoriasis with indiscriminate systemic corticosteroid use for a prolonged period. A single patient can be victim of multiple deleterious effects of corticosteroids. The aim of this case discussion is not only to describe the myriads of sequels of corticosteroid misuse effecting musculoskeletal system severely but simultaneously to rethink about prescription of steroid in psoriasis, too.
\end{abstract}

Key words: Psoriasis; Misuse; Adverse effects; musculoskeletal.

\section{INTRODUCTION}

The use of systemic steroids in the treatment of psoriasis is not recommended. Nonetheless, recent literature revealed that systemic steroids have been the most frequently prescribed drugs for psoriasis by general practitioners, and some physicians and dermatologists ${ }^{1}$. Despite the bad sequel of systemic corticosteroid is well-recognized, it is not uncommon in clinical practice to encounter with patients abused by corticosteroid. This is a case history of a middle-aged male with psoriasis with systemic corticosteroid misuse for prolonged period. The aim of this case discussion is to describe as well as make a flashback of the inevitable effects of systemic corticosteroid misuse.

\section{CASE HISTORY}

A 52 years male, occasional alcoholics but nonsmoker had been diagnosed as a patient of psoriasis for about 8 years. He got admitted to the department of dermatology for flare of psoriasis with hip pain and aggravated low back pain. $\mathrm{He}$ had itchy skin lesion on his back, both elbow, both knee, extensor surface of both ankle and in his palms and soles (Figure 1). His nails of fingers and toes had the typical features of psoriasis including, pitting, onycholysis, subungual hyperkeratosis etc (Figure 1). He also gave history of chronic low back pain, multiple joint pains but could not specify the joints. There was also history of taking oral prednisolone (60 $\mathrm{mg}$ /day for for 7 days followed by tapering doses) several times for severe psoriatic flares. His back pain was inflammatory type in nature. He gave no history of weight loss, his appetite was good. General examination revealed mild anaemia, face was puffy, wasting of limb muscles with protruded abdomen (Figure 2). The skin lesions were well circumscribed, dry, erythematous plaques with silver scales and appearance of bleeding points on removal of the scales (Auspitz sign). He had generalized muscle wasting. His blood pressure was $145 / 96 \mathrm{mmHg}$ and temperature was $97.6^{0}$ F. Systemic evaluation showed abnormalities mostly on musculoskeletal system. Spine was restricted in all direction. FABER test was positive on left side. 
No other joint tenderness was found except both in hip with restricted movement. Nodular thickening of skin of right palm with flexion deformity of right little and ring finger was evaluated. Haematology revealed mild anaemia ( $\mathrm{Hb} 10 \mathrm{gm} / \mathrm{dl}$ ), Erythrocyte sedimentation rate $20 \mathrm{~mm}$ in $1^{\text {st }}$ hour, WBC was within normal range, RA and tuberculin tests were negative. Radiology showed osteonecrosis of both hip joints (Figure 3), generalized osteopenia of the spine with wedge fracture of D11 and L1 vertebra (Figure 4).

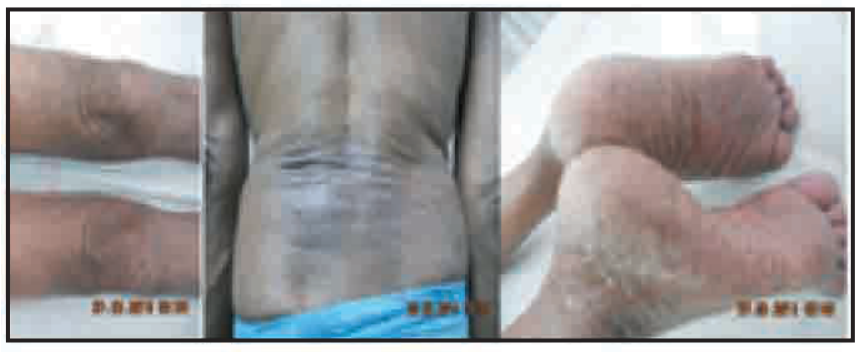

Figure 1A: Psoriatic skin lesions: On both the knees, the back and the soles

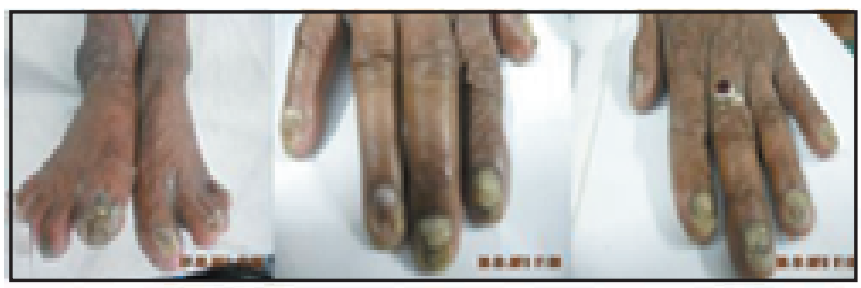

Figure 1B : Psoriatic nail changes in fingers and toes, pitting, onycholysis and hyperkeratosis

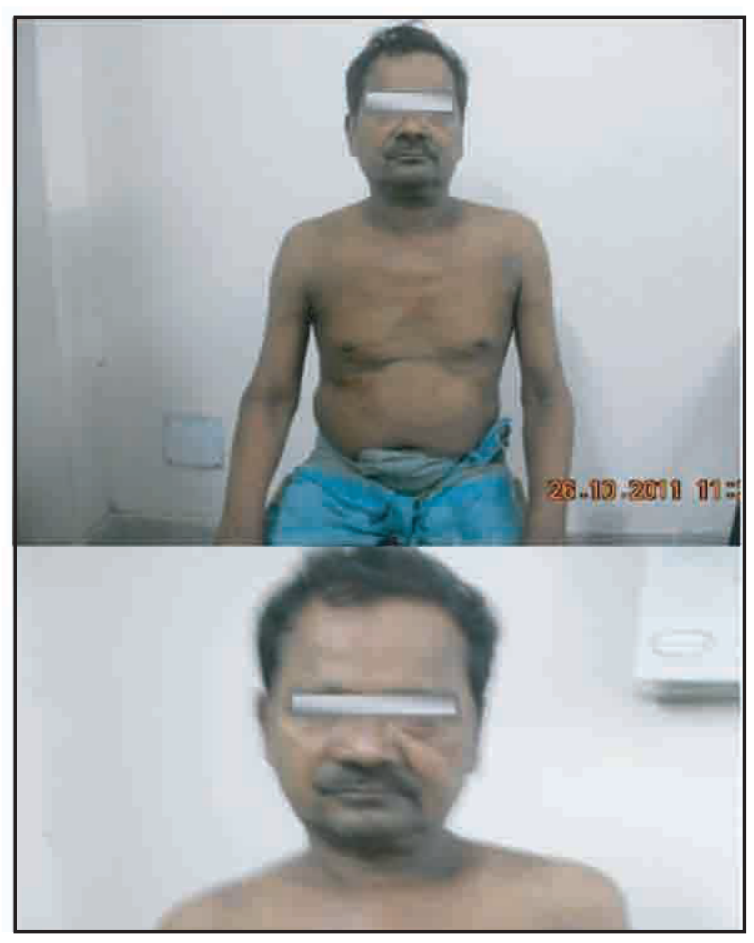

Figure 2 : Some sequels of corticosteroid misuse. Puffy face, abdominal obesity with thinning of the limbs are seen

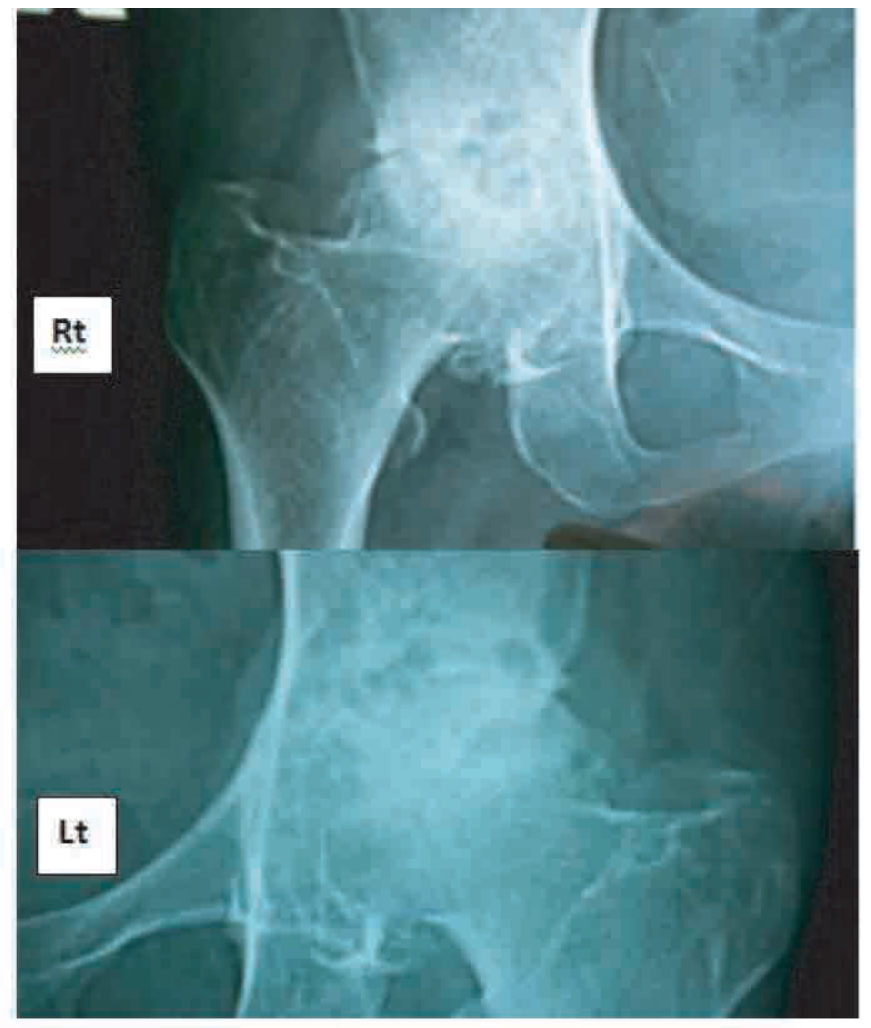

Figure 3 : Steroid induced osteonecrosis of both hip with secondary osteoarthritic changes

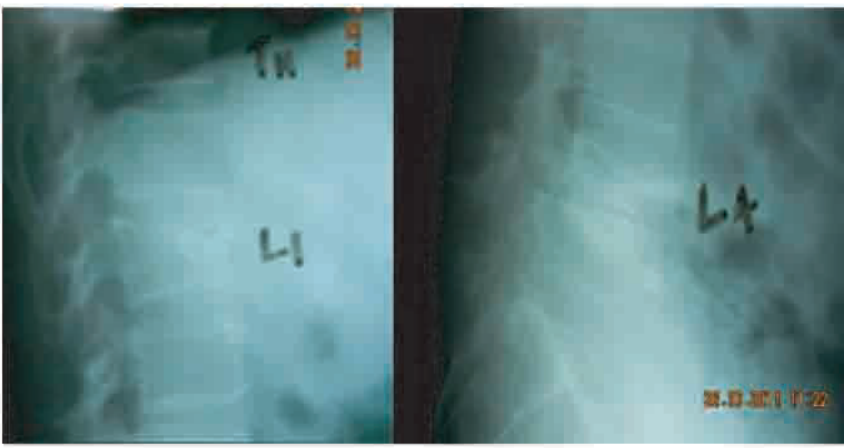

Figure 4 : Compression fracture of T11, L1 and L4 vertebra with L4 listhesis, generalized rarefaction (Osteopenia) of spine

\section{DISCUSSION}

Corticosteroids are used in a wide variety of diseases including rheumatic disorders, autoimmune disorders, and other inflammatory conditions. However, the long-term use of corticosteroids has variable effects on bone morphology and metabolism ${ }^{2}$. Long-term corticosteroid use has been related to impaired calcium absorption from the gut, and increased loss in the kidneys. Corticosteroids also impact bone turnover through inhibition of osteoblast proliferation and function, with an increase in osteoblast and osteocyte apoptosis. In addition, longterm steroid use may inhibit insulin-like growth factor and collagen $^{3}$. These effects may lead to an increased risk of fractures. 
Osteonecrosis is a serious complication of corticosteroid use and occurs in $5-25 \%$. The risk increases with both dose and duration of treatment. Steroid use is the commonest cause of osteonecrosis ${ }^{4}$.The femoral head is most frequently involved but other large joints may be affected ${ }^{5}$. During corticosteroid use there is a reduction in muscle protein synthesis and protein catabolism; therefore, muscle weakness and loss of bulk can occur. In its extreme form a steroid myopathy may develop, affecting the proximal muscles. Corticosteroid use is associated with sodium and water retention, resulting in hypertension ${ }^{6}$.

Although treatment with oral corticosteroids is known to decrease bone density, there are few data on the attendant risk of fracture. However, a study in UK showed that fracture risks declines toward baseline rapidly after cessation of oral corticosteroid treatment indicating implication of corticosteroid use in fracture risk ${ }^{7}$. The anaemia can be explained by psoriasis patient since it is an autoimmune and chronic disease. The dupuytren's disease in this case might be due to alcohol intake.

\section{CONCLUSION}

A re-evaluation of the treatment of psoriasis with or without psoriatic arthritis with systemic steroids is necessary in order to speculate the risk benefit ratio once again.

\section{ACKNOWLEDGEMENTS}

We are grateful to this patient for permitting us to publish his report. Also we are grateful to the Department of Dermatology for their cooperation.

\section{DISCLOSURE}

All the authors declared no competing interest.

\section{REFERENCES}

1. Mrowietz U, Domm S. Systemic steroids in the treatment of psoriasis: what is fact, what is fiction? J Eur Acad Dermatol Venereol. 2013;27(8):1022-1025

2. Hetsroni I, Markushevitz M, Nyska M. Bilateral Femoral Neck Fractures in Long-term Steroid Use for Systemic Lupus Erythematosus and Chronic Lung Disease. Orthopedics. 2008; 31(2):180.

3. Patschan D, Loddenkemper K, Buttgereit F. Molecular mechanisms of glucocorticoid-induced osteoporosis. Bone. 2001; 29(6):498-505.

4. Coombs RRH, Thomas RdeWM. Avascular necrosis of the hip. Br J Hosp Med. 1994;51:275-280

5. Craddock CG. Corticosteroid-induced lymphopenia, immunosuppression and body defence. Ann Intern Med. 1978;88:564.

6. M Stanbury RM, Graham EM. Systemic corticosteroid therapy-side effects and their management. Br J Ophthalmol. 1998;82:704-708

7. Van Staa TP, Leufkens HG, Abenhaim L, Zhang B, Cooper C. Use of oral corticosteroids and risk of fractures. J Bone Miner Res. 2000;15(6):993-1000. 